\title{
DEPÓSITOS FLÚVIO-EÓLICOS DA FORMAÇÃO SÃO SEBASTIÃO, NA BORDA OESTE DA BACIA DE JATOBÁ, NORDESTE DO BRASIL
}

\author{
José Diego Dias Veras ${ }^{1}$ \\ Virgínio Henrique de Miranda Lopes Neumann ${ }^{2}$ \\ Lúcia Maria Mafra Valença ${ }^{2}$ \\ Flávia Araújo de Arruda Cabral ${ }^{2}$ \\ Silvio Roberto de Oliveira ${ }^{3}$ \\ 10.18190/1980-8208/estudosgeologicos.v28n2p3-18 \\ ${ }^{1}$ Programa de Pós-Graduação em Geociências-UFPE, diegodias_ig@ hotmail.com \\ 2Departamento de Geologia -UFPE, neumann@ufpe.br; $\underline{\text { lmmv@ufpe.br; }}$ \\ flaviaaraujo7@hotmail.com \\ ${ }^{3}$ Grupo João Santos - Cimento Nassau

\begin{abstract}
RESUMO
A Bacia de Jatobá, juntamente com a Sub-bacia de Tucano Norte, representam a extremidade setentrional do Sistema Rifte Recôncavo-Tucano-Jatobá, que possui direção geral N-S até a altura do Rio São Francisco, onde sofre uma inflexão para E-NE. Ao contrário das bacias da margem continental que evoluíram ao estágio de margem passiva, as Bacias Recôncavo, Tucano e Jatobá, constituem um ramo do Rifte Sul-Atlântico abortado no Eoaptiano. A Formação São Sebastião está inserida no estágio rifte da Bacia de Jatobá. Possui uma fácies fluvial que é composta por arenitos finos a grossos, por vezes conglomeráticos e, localmente, níveis seixosos. Os perfis estratigráficos realizados nesta fácies e a associação de fácies ressaltam suas características de composição e estruturas. A fácies eólica apresenta uma característica marcante como a sua bimodalidade no tamanho dos grãos de quartzo. Além disso, as estratificações cruzadas de alto ângulo corroboram a definição de ambiente eólico. São arenitos finos, às vezes médios, bem selecionados e variando de esbranquiçados a amarelados. Portanto, esta unidade é caracterizada como um sistema fluvial entrelaçado de alta energia que, posteriormente, passa por um retrabalhamento eólico.
\end{abstract}

Palavras Chaves: Bacia do Jatobá, Sub-bacia Tucano Norte, Depósitos flúvio-eólicos, Formação São Sebastião

\begin{abstract}
The Jatobá Basin, together with the North Tucano Sub-basin, represent the northern extremity of the Rift Recôncavo-Tucano-Jatobá System, which has a general N-S direction up to the São Francisco River, where it undergoes an inflection into E-NE. Unlike the continental margin basins that evolved to the stage of passive margin, the Recôncavo, Tucano and Jatobá basins constitute a branch of the South Atlantic Rift aborted in the Eoaptian. The São Sebastião Formation is part of the rift stage of the Jatobá Basin. It has a fluvial facies that is composed of fine to thick sandstones, sometimes conglomeratic, and, locally, seedy levels. The stratigraphic profiles performed in this facies and the association facies highlight its characteristics of composition and structures. The wind facies presents a striking characteristic as its bimodality in the size of the quartz grains. In addition, cross-stratified high-angle corroborate the definition of wind environment. They are fine sandstones, sometimes medium, well selected and varying from whitish to yellowish. Therefore, this unit is characterized as a high-energy braided fluvial environment that, afterwards, undergoes a wind reworking.
\end{abstract}

Keywords: Jatoba Basin, Tucano Norte Sub-basin, Fluvio-Eolic deposits, São Sebastião Formation 


\section{INTRODUÇÃO}

A evolução do conhecimento sobre a Bacia de Jatobá é constante, assim como, a maioria das bacias sedimentares brasileiras, através de pesquisas acadêmicas e de empresas da iniciativa privada. A associação de diversos artigos, dissertações, teses fornecem resultados para a adaptação e modificação da coluna estratigráfica proposta por Costa et al. (2007) em sua revisão publicada no Boletim de Geociências da Petrobras.

Diante disso, a bacia tem sido compreendida como parte integrante do Sistema Recôncavo-Tucano-Jatobá (RTJ), além de possuir diversos estudos (acadêmicos e técnicos) que corroboram a sua correlação estratigráfica com outras bacias interiores do nordeste brasileiro.

Dentro desse conteúdo de estudos de visão macro, está a Formação São Sebastião, objeto de estudo do presente trabalho. Trabalhos anteriores são fortemente reconhecidos por seus conteúdos e inovações referentes à esta unidade sedimentar correspondente à fase rifte da bacia. Fambrini et al. (2006, 2007, 2013) e Guzmán-González et al. (2015) são trabalhos fundamentais sobre a unidade que exploram, com especialidade, as fácies e os sistemas deposicionais.

Este trabalho objetivou integrar as informações disponíveis através da revisão bibliográfica, acerca da Formação São Sebastião, com os novos dados obtidos em campo para formalizar em forma de artigo, uma nova contribuição para a evolução do conhecimento.

\section{LOCALIZAÇÃO}

A Bacia de Jatobá localiza-se na porção centro-sul do Estado de Pernambuco. O domínio de estudo está inserido na Mesorregião Sertão Pernambucano e Microrregião Itaparica, compreendendo os municípios de Floresta e Petrolândia nas porções norte e sul da área mapeada, respectivamente (Fig.1). A Formação São Sebastião, objetivo deste trabalho, está identificada de acordo com o mapa geológico da figura 2 .

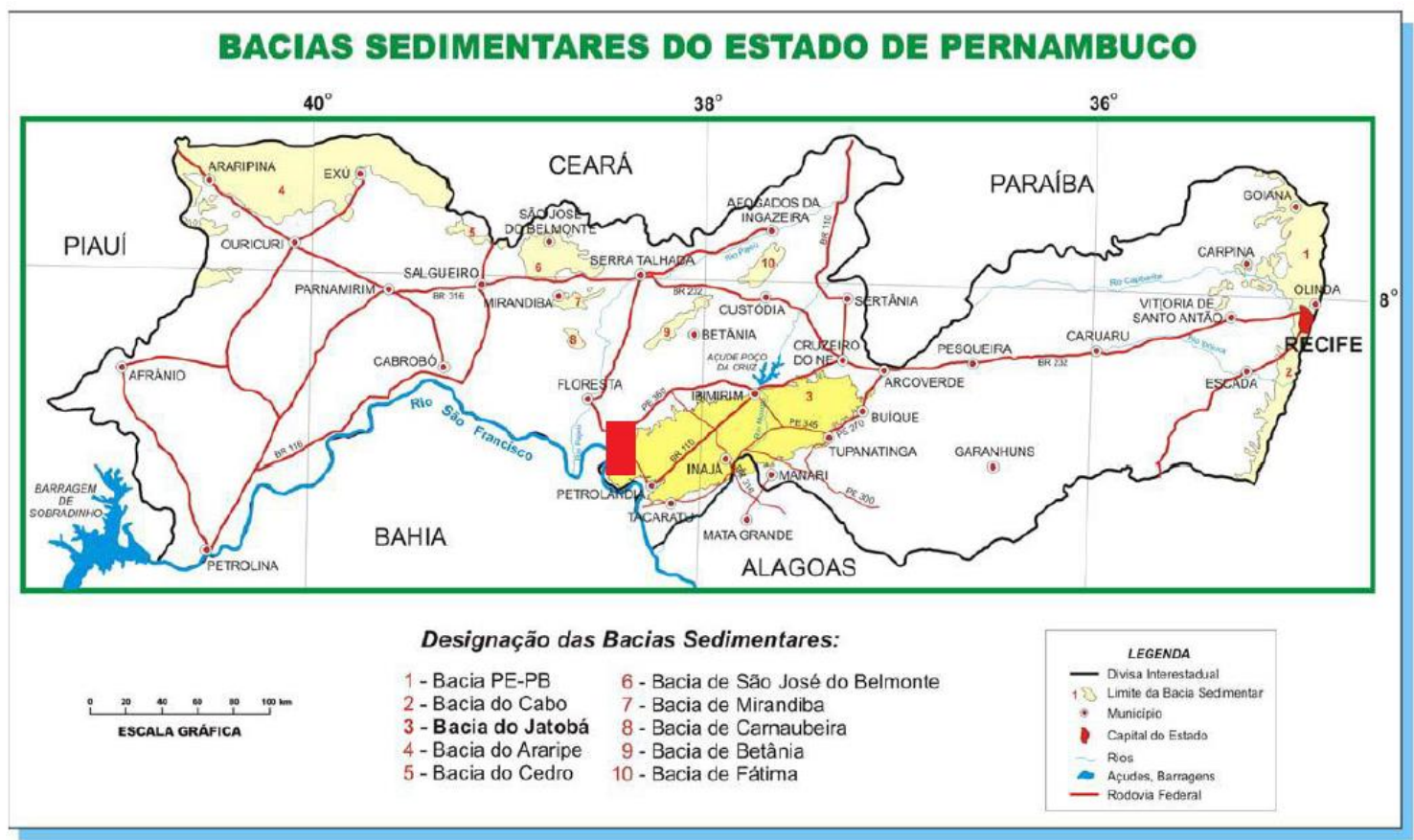

Figura 1. Mapa de localização das bacias sedimentares de Pernambuco. O retângulo em vermelho representa a área de estudo. 


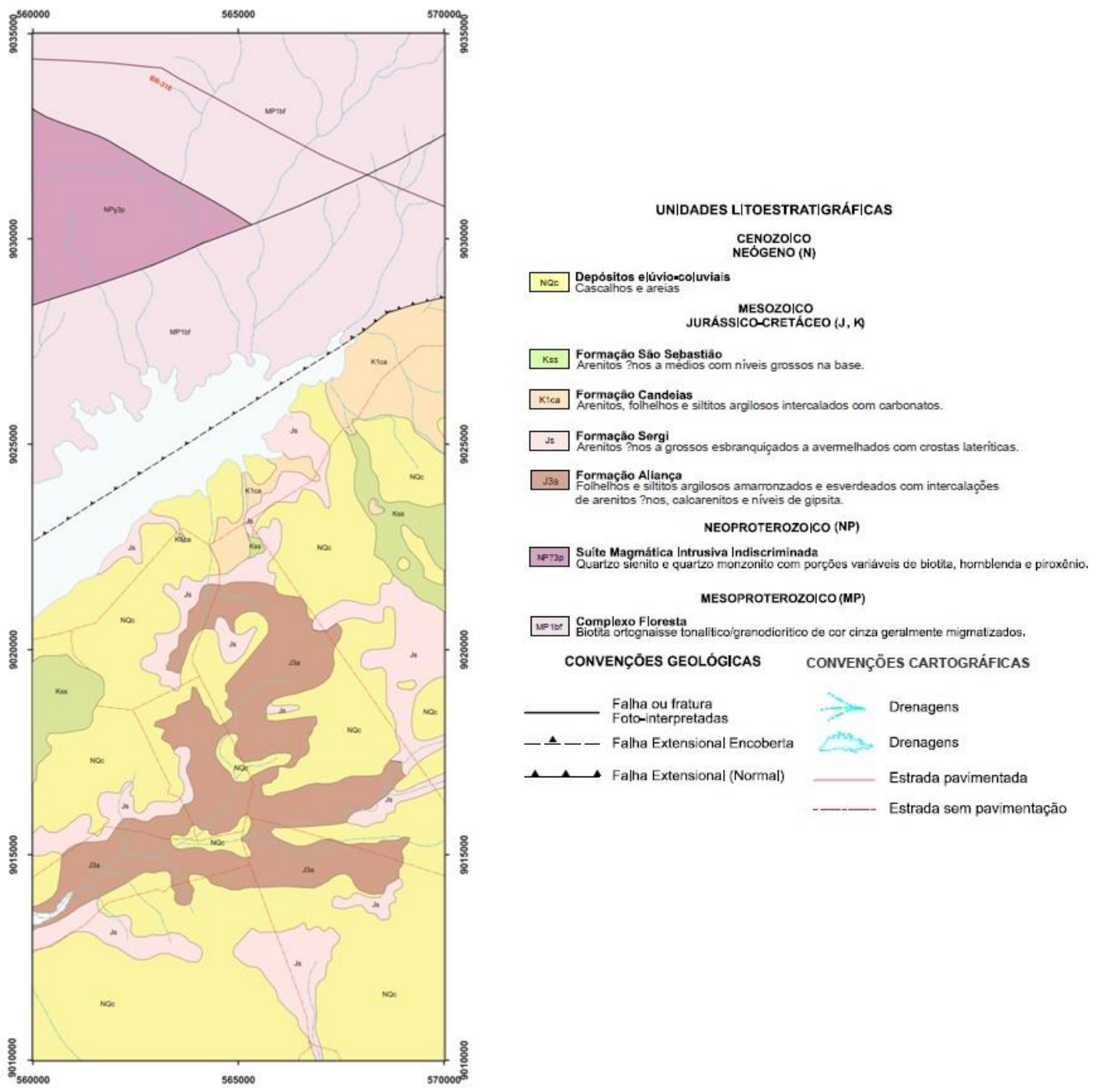

Figura 2. Mapa geológico da região estudada (Veras et al., 2017).

\section{MATERIAIS E MÉTODOS}

Inicialmente, foi realizado um levantamento bibliográfico sobre a Bacia de Jatobá, assim como as fácies dos depósitos sedimentares aqui estudados (como exemplo, Miall (1996) e Mountney (2006)), de modo a agrupar as informações necessárias que pudessem colaborar para o desenvolvimento deste estudo.

Em seguida foi realizada fotointerpretação da área da região a partir de fotografias aéreas na escala de 1:70.000 de 1965 da SUDENE. As fotos foram interpretadas através de estereoscopia digital. O resultado da interpretação das fotografias aéreas foi interpolado com o mapa geológico elaborado pela CPRM (Leite et al., 2001) na escala de 1:250.000, o que possibilitou a elaboração de um mapa preliminar e identificação de possíveis locais de ocorrência da Formação São Sebastião.

Em seguida foram realizadas as etapas de campo. Os afloramentos identificados foram geoposicionados utilizando coordenadas UTM em Datum WGS84, Zona 24L, fotografados e devidamente descritos. Além das descrições, foram realizados dois perfis estratigráficos com a finalidade de identificar as estruturas e fácies sedimentares. 
Por fim, a análise petrográfica de 06 (seis) amostras coletadas em campo de ambas as fácies (classificadas de acordo com Folk, 1968), onde as lâminas foram estudadas no Laboratório de Microscopia Óptica do Departamento de Geologia da UFPE.

\section{GEOLOGIA REGIONAL}

A Bacia de Jatobá ocupa uma área de aproximadamente $\quad 5.000 \quad \mathrm{~km}^{2}$ com orientação NE-SW. Está limitada pela falha de Ibimirim ao norte, pela falha de São Francisco, que a separa da sub-bacia Tucano Norte a oeste, e pela borda flexural, nas demais direções (Costa et al., 2007).

Juntamente com a Sub-bacia de Tucano Norte, representam a extremidade setentrional do Sistema Rifte RecôncavoTucano-Jatobá que possui direção geral N$\mathrm{S}$ até a altura do Rio São Francisco, onde sofre uma inflexão para E-NE, estando sua origem relacionada à extensão crustal que fragmentou o Supercontinente Gondwana, dando origem ao Oceano Atlântico.

O presente trabalho adota a divisão estratigráfica de sucessão sedimentar proposta por Neumann et al., (2010), que revisando a Formação Santana de Rocha \& Leite (1999), que se basearam na análise de sequências realizadas por Ponte et al., (1997), a redefiniram como Grupo Santana, representado pelas Formações Crato e Romualdo. De acordo com Neumann et al., (2010), a Bacia de Jatobá possui uma estratigrafia semelhante à da Bacia do Araripe, e por isso definiram cinco sequências estratigráficas para a mesma: (1) tectono-sequência Beta, representada pelas formações Tacaratu e Inajá; (2) tectono-sequência Pré-Rifte, representada pelas formações Aliança e Sergi; (3) tectono-sequência Rifte, representada pelas formações Candeias, São Sebastião e o Grupo Ilhas; (4) tectono-sequência PósRifte, represen-tada pelas formações Marizal, Crato, Romualdo e Exu; (5) tectono-sequência Zeta, compreende as coberturas terrígenas continentais, representadas pelos depósitos eluviais/coluviais e aluvionares.

A Formação São Sebastião possui idade eocretácica e representa a última unidade estratigráfica da tectono-sequência Rifte. Estende-se em parte da porção setentrional da bacia, desde a região situada a SSW do povoado de Campos, até a SSW do horst de Serrotinho, borda NW da Bacia de Jatobá.

Litologicamente essa unidade está caracterizada por arenitos finos a médios, com níveis grossos na base. Apresenta estratificações cruzadas acanaladas de grande porte e plano-paralelas de forma subordinada como suas estruturas sedimentares mais representativas. Geralmente observam-se serras arredondadas ou morrotes ondulados, e mais raramente, serras escarpadas.

Conforme Rocha \& Leite (1999), Fambrini et al., (2006, 2007) e GuzmánGonzález et al., (2015) o conjunto de características litológicas e estruturais indicam um ambiente de sedimentação fluvial de alta energia, com gradação para um ambiente desértico, tipicamente eólico. O contato inferior da Formação São Sebastião com os sedimentos do Grupo Ilhas é transicional, enquanto que o superior com a Formação Marizal é do tipo discordante erosivo/angular (Bruni et al., 1976).

\section{RESULTADOS E DISCUSSÕES}

Esta unidade ocorre na porção central da área de estudo, e juntamente com a Formação Candeias e o Grupo Ilhas, está inserida na Fase Rifte com seus depósitos sedimentares. Litoestratigraficamente, a Formação São Sebastião recobre os depósitos do Grupo Ilhas e da Formação Candeias, e está subjacente aos depósitos da Formação Marizal (Fase Pós-Rifte).

Por se tratar de um sistema fluvial de alta energia com retrabalhamento eólico, esta unidade pode ser subdividida em duas fácies através das observações realizadas em campo juntamente com os estudos 
petrográficos, com características bem marcantes, a fácies fluvial e a fácies eólica.

\section{Sequência Fluvial}

Sendo o primeiro ciclo de deposição da Formação São Sebastião, a fácies fluvial caracteriza um depósito siliciclástico de alta energia que é composto por arenitos finos a grossos, por vezes conglomeráticos e em alguns afloramentos observa-se a presença de níveis seixosos. Apresentam uma coloração variada (esbranquiçados, amarelados e avermelhados) e grãos de quartzo com arredondamento entre angulosos e arredondados (Fig. 3 e 4).

Também foram identificadas algumas estruturas, tais como laminação, estratificação, estruturas de escape, que foram melhor registradas em seções estratigráficas realizadas em dois afloramentos (Fig. 5 e 7) nesta fácies fluvial com o intuito de obter uma melhor caracterização dessa litologia. As ilustrações dessas seções são mostradas a seguir (Fig. 6, 8 e 9).

Agrupando as informações obtidas através das seções estratigráficas realizadas em campo foi possível determinar uma associação de fácies de acordo com a tabela 1.

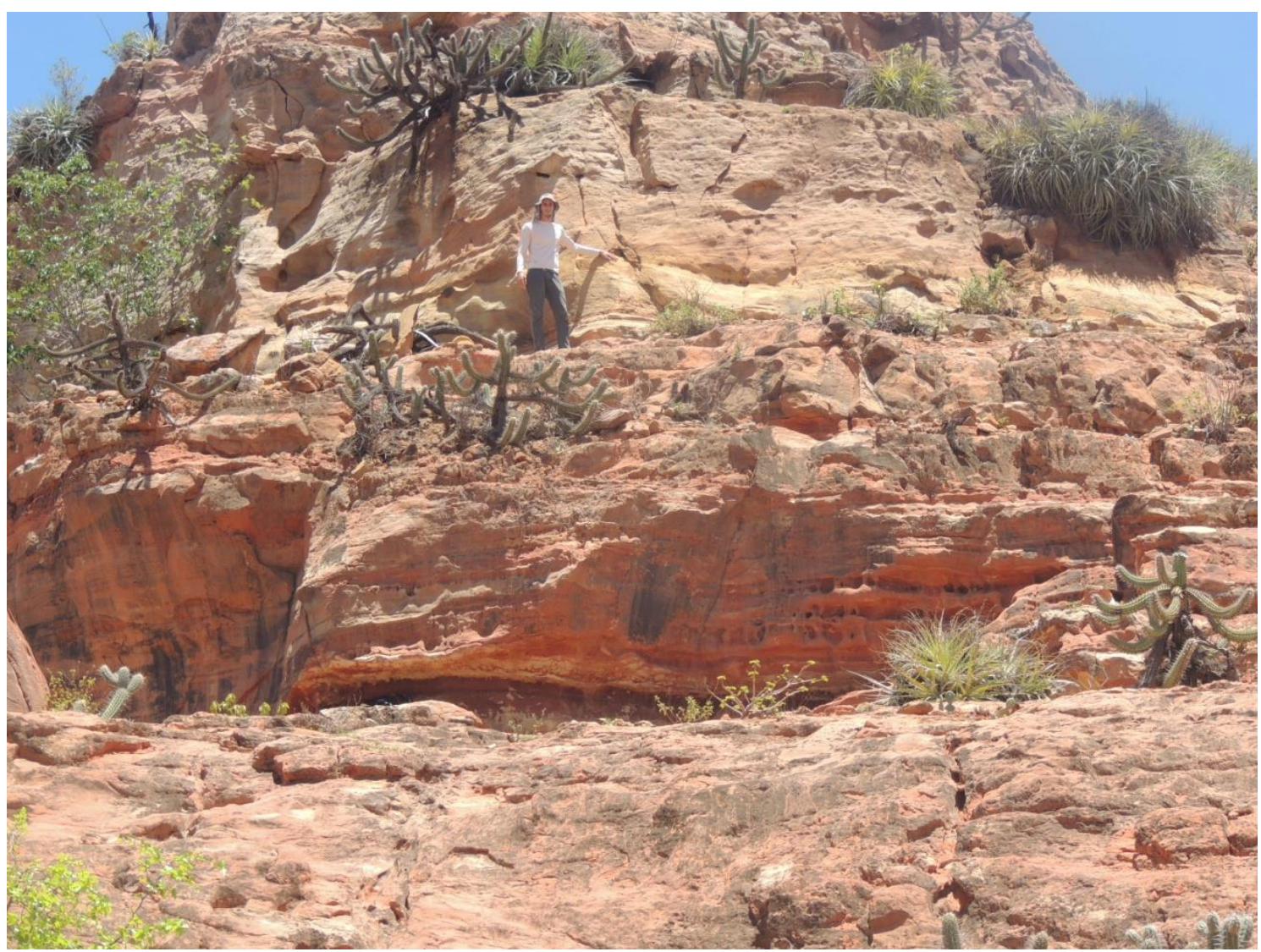

Figura 3. Afloramento da fácies fluvial da Formação São Sebastião. 


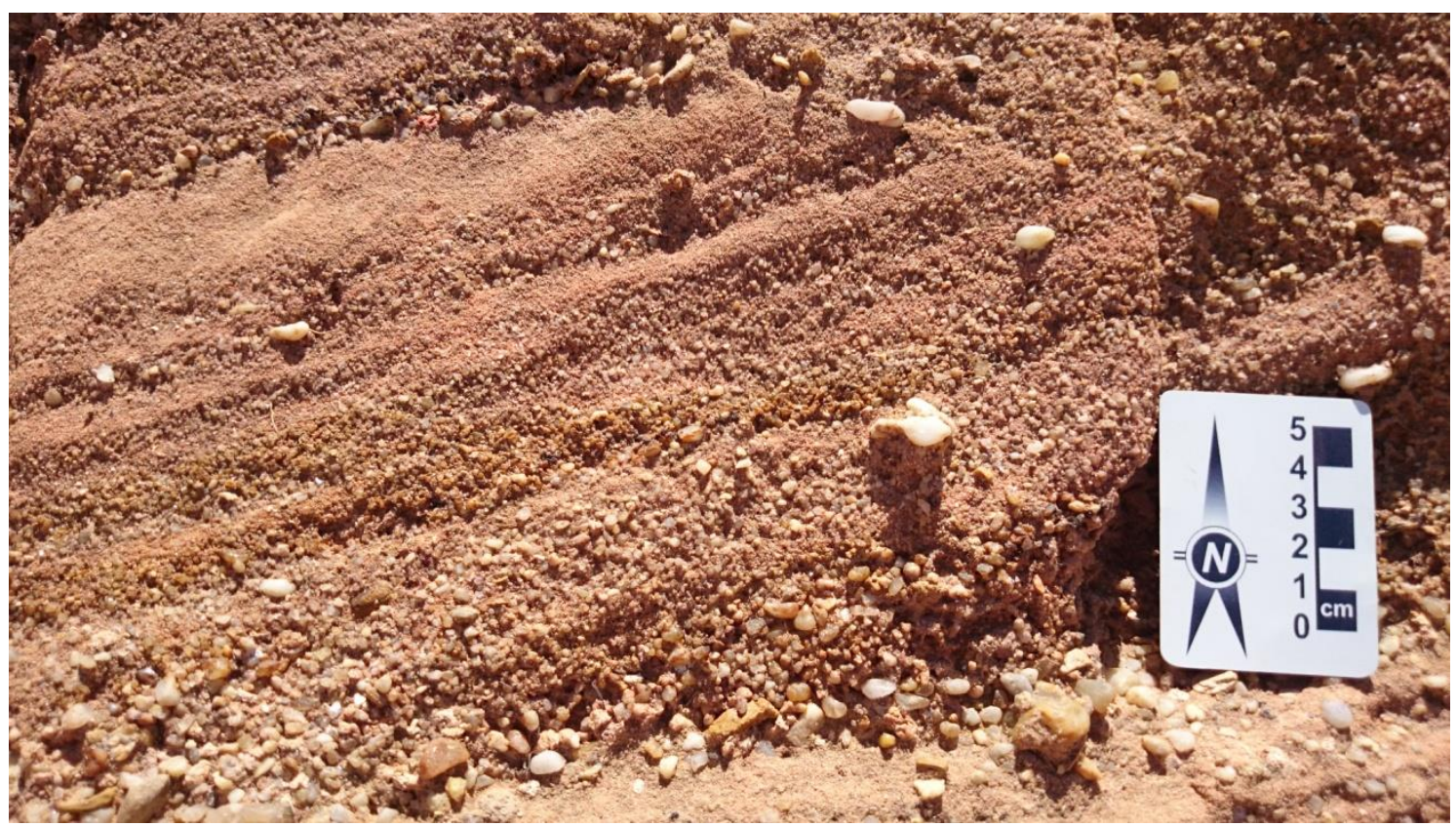

Figura 4. Variação granulométrica da fácies fluvial da Formação São Sebastião juntamente com estratificação cruzada planar.

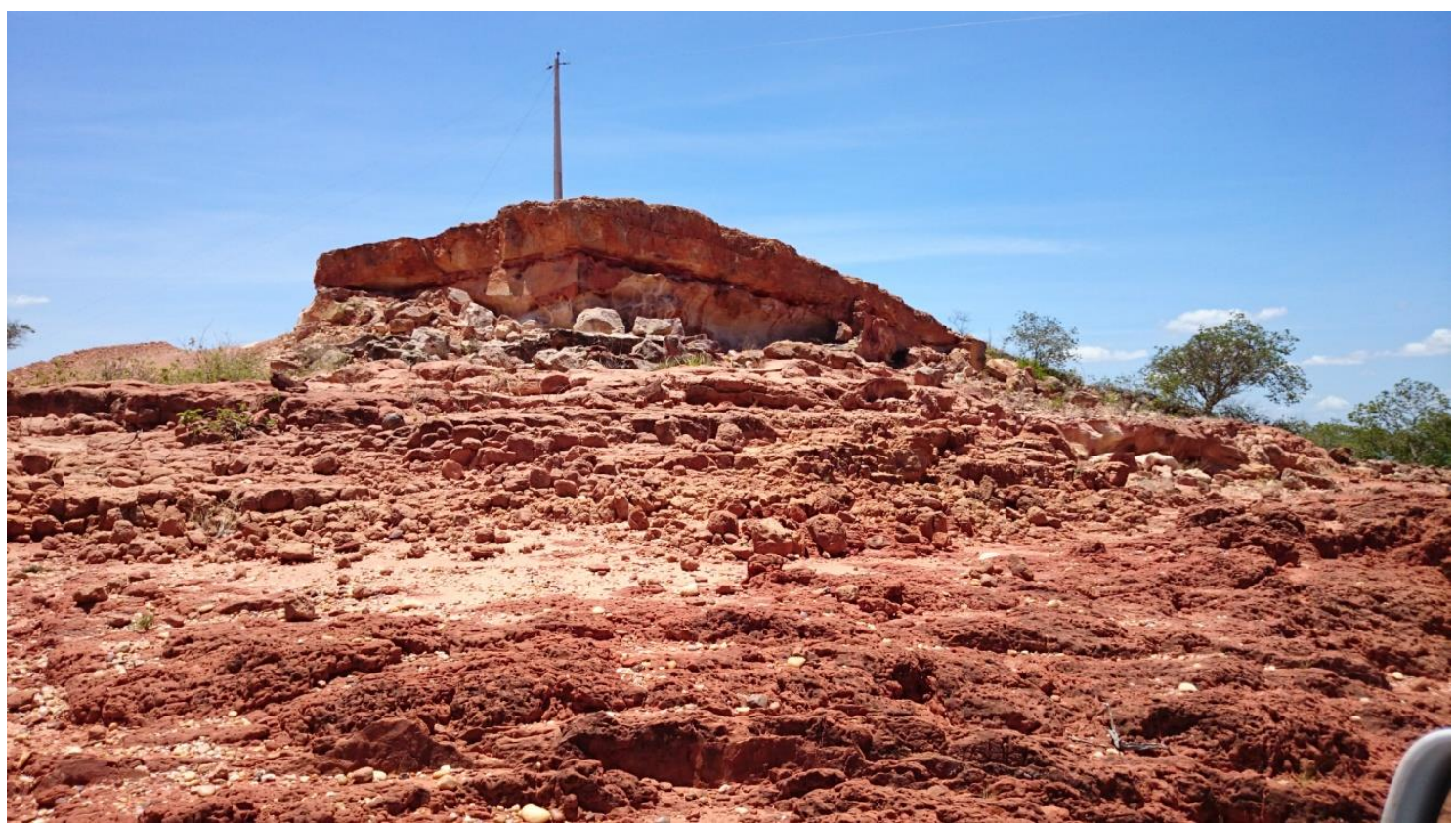

Figura 5. Afloramento da Seção Estratigráfica 1. 


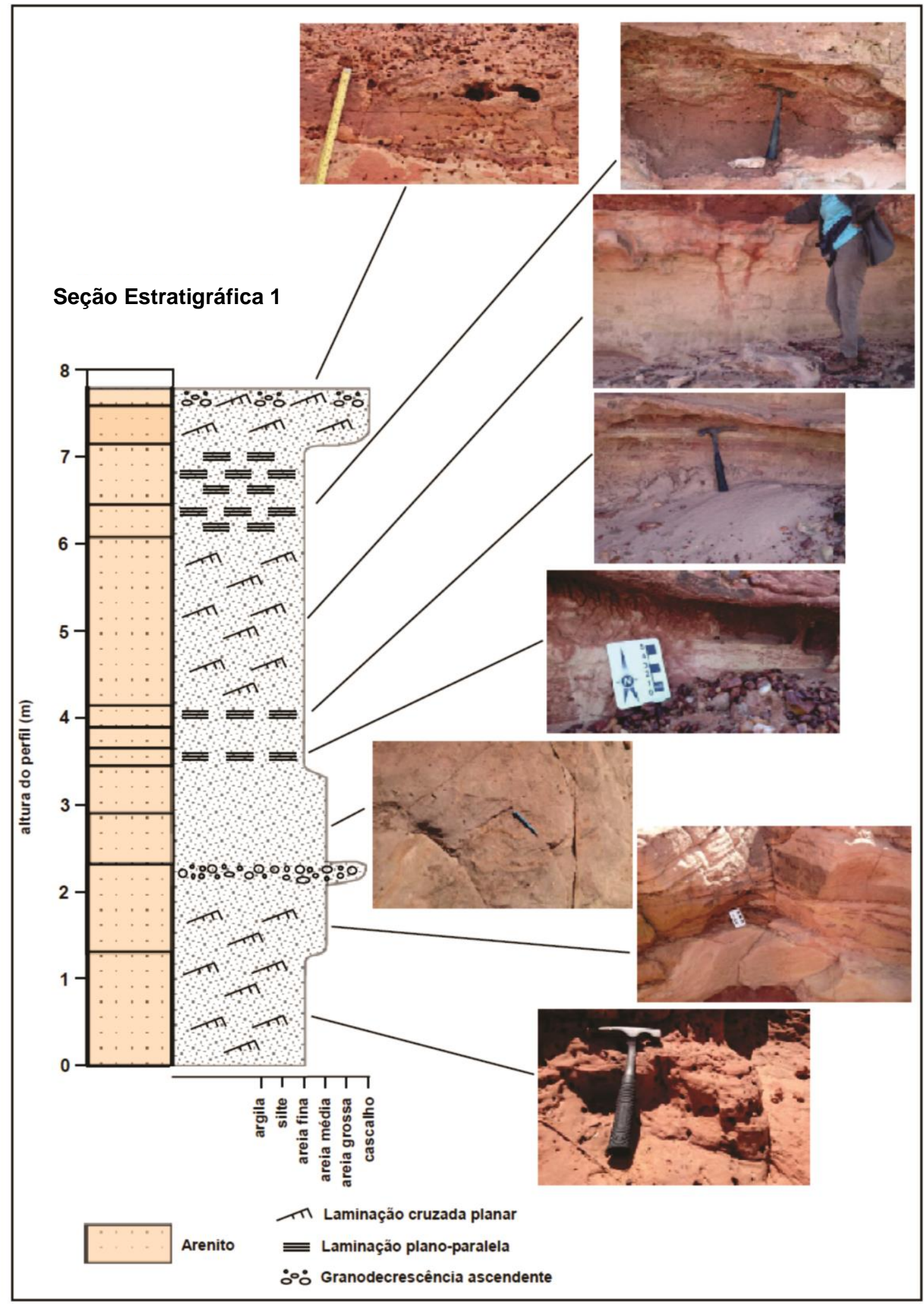

Figura 6. Seção Estratigráfica 1. 


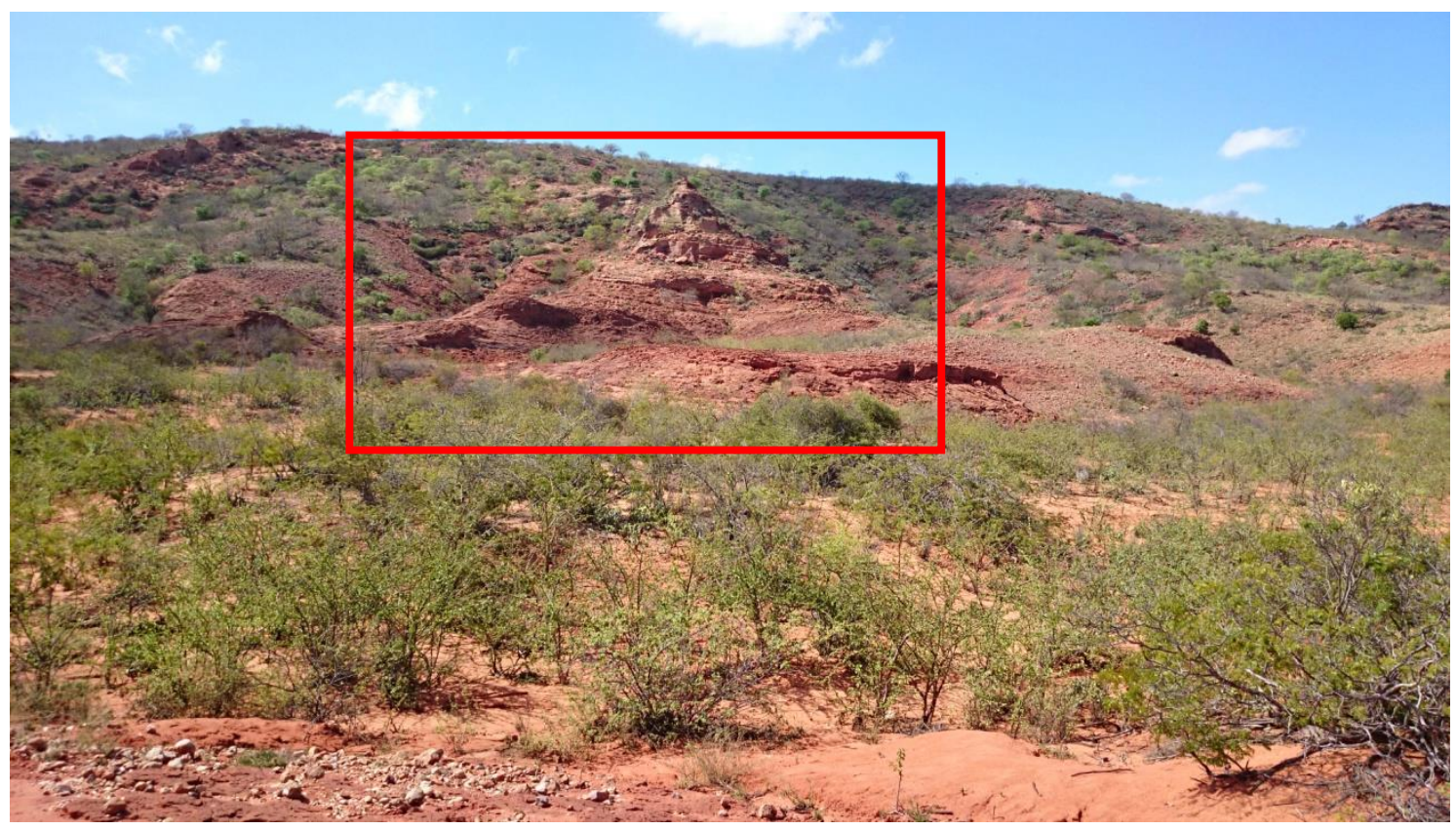

Figura 7. Afloramento da Seção Estratigráfica 2. 


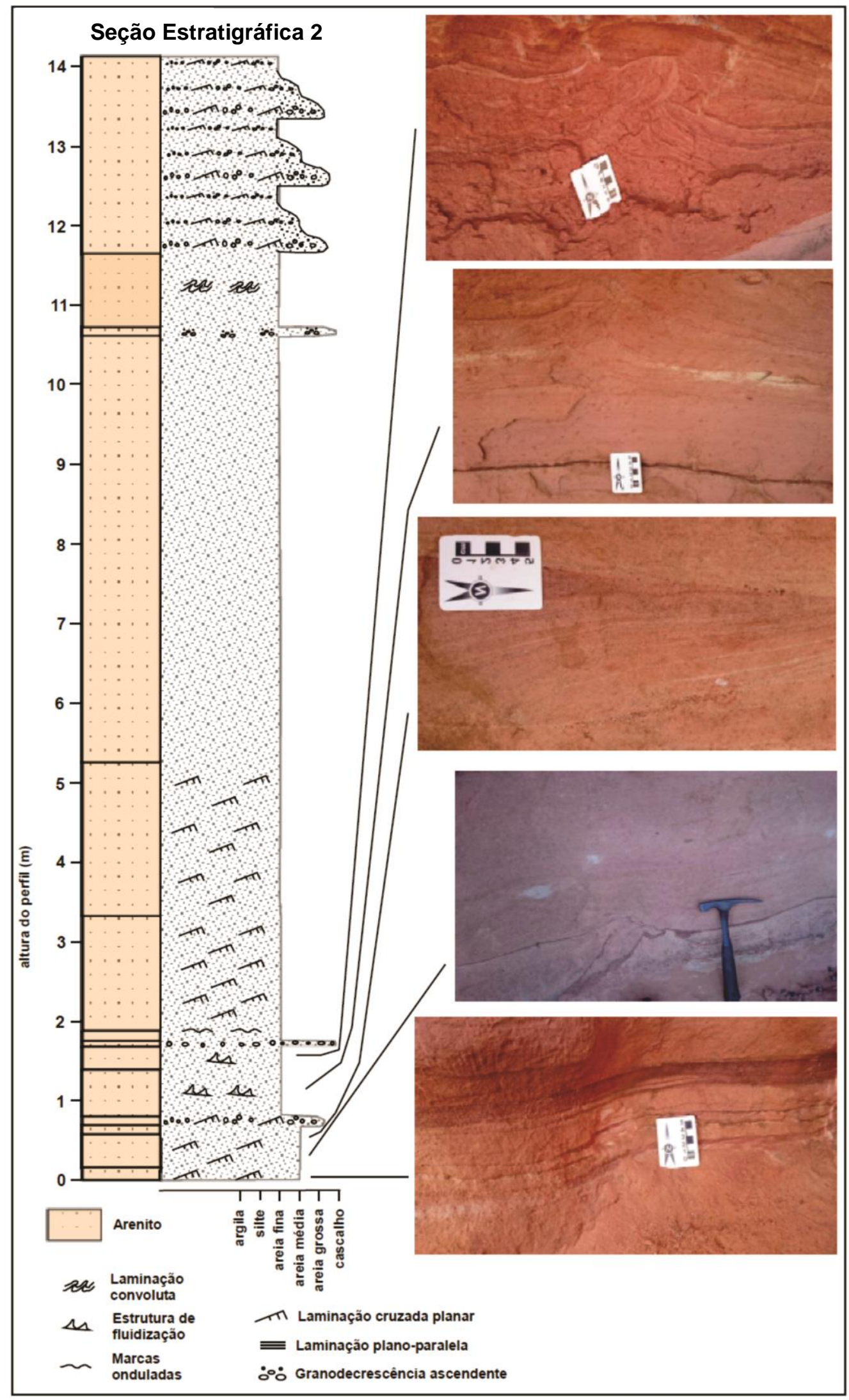

Figura 8. Seção Estratigráfica 2. 


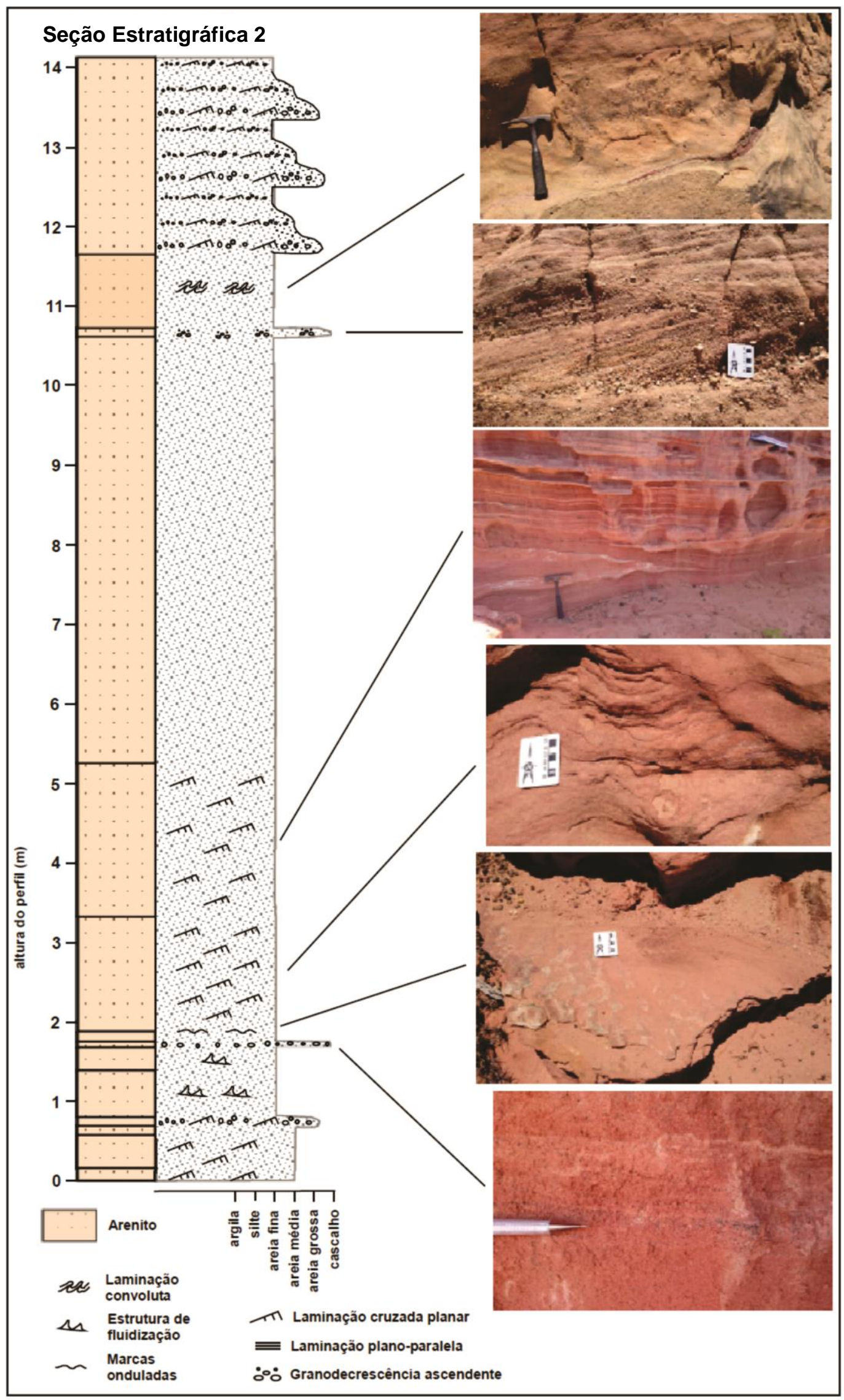

Figura 9. Seção Estratigráfica 2. 
DEPÓSITOS FLÚVIO-EÓLICOS DA FORMAÇÃO SÃO SEBASTIÃO...

Tabela 1. Associação de fácies construída a partir dos dados obtidos em campo.

\begin{tabular}{|c|c|c|c|}
\hline CÓDIGO & FÁCIES & DESCRIÇÃO & INTERPRETAÇÃO \\
\hline $\mathbf{A}_{\mathbf{m}}$ & Maciço & $\begin{array}{l}\text { Arenito maciço e com granulação variando de muito fino à médio. } \\
\text { Apresenta uma má selecão, mas localmente é bem selecionado e sua } \\
\text { coloração varia entre tons esbranquiçados e amarelados. }\end{array}$ & Eventos de transbordamento de canal fluvial. \\
\hline $\mathbf{A}_{\mathbf{l}}$ & $\begin{array}{l}\text { Laminação } \\
\text { Plano- } \\
\text { paralela }\end{array}$ & $\begin{array}{c}\text { Arenito com laminação plano-paralela com granulação variando de } \\
\text { muito fino à fino. Apresenta uma seleção variada de mal a bem } \\
\text { selecionado e sua coloração varia entre tons esbranquiçados, } \\
\text { amarelados e avermelhados. }\end{array}$ & $\begin{array}{c}\text { Sedimentação de leito sob regime de fluxo } \\
\text { superior. }\end{array}$ \\
\hline $\mathbf{A}_{d}$ & $\begin{array}{l}\text { Arenitos } \\
\text { Deformados }\end{array}$ & $\begin{array}{l}\text { Arenito apresentando estruturas de deformação (laminação } \\
\text { convoluta), granulação fina e coloração avermelhada. }\end{array}$ & $\begin{array}{l}\text { Estruturas sin-sedimentares causadas por escape } \\
\text { de fluidos ou diferença no caráter reológico das } \\
\text { camadas adjacentes. }\end{array}$ \\
\hline $\mathbf{A}_{\mathbf{c}}$ & $\begin{array}{l}\text { Estratificação } \\
\text { Cruzada }\end{array}$ & $\begin{array}{l}\text { Arenito com estratificação cruzada planar com níveis } \\
\text { conglomeráticos. Sua coloração varia entre tons amarelados e } \\
\text { avermelhados. Localmente apresenta granodecrescência ascendente. }\end{array}$ & $\begin{array}{l}\text { Sistemas fluviais de alta energia, exemplo: barras } \\
\text { de canais entrelaçados. }\end{array}$ \\
\hline
\end{tabular}


A análise petrográfica das amostras coletadas em afloramentos da Formação São Sebastião constatou uma mineralogia composta essencialmente por quartzo, com a presença de pouquíssimos grãos de plagioclásio, micas e fragmentos líticos, quase que inexistentes para a fácies fluvial (Fig. 10).

Entre os grãos de quartzo existe uma predominância de policristalinos apresentando extinção ondulante, mas também há a presença de grãos monocristalinos. Os grãos de quartzo apresentam-se anédricos, assim como os plagioclásios.

É composto de uma cimentação por argilominerais apresentando, também, cimentação por óxido/hidróxido de ferro. As amostras apresentam uma textura sustentada pelos grãos, que possuem uma granulação variada de fina a grossa, ocasionando assim, consequentemente, uma variação na seleção, onde existem amostras com boa e má seleção. Os grãos variam 0 arredondamento entre subarredondados à subangulosos, mas alguns se destacam por serem mais arredondados ou mais angulosos, assim como sua esfericidade, onde predomina a baixa, mas ainda sim, alguns grãos se sobressaem apresentando alta esfericidade. Apresentam um empacotamento normal, de acordo com Khan, 1956.

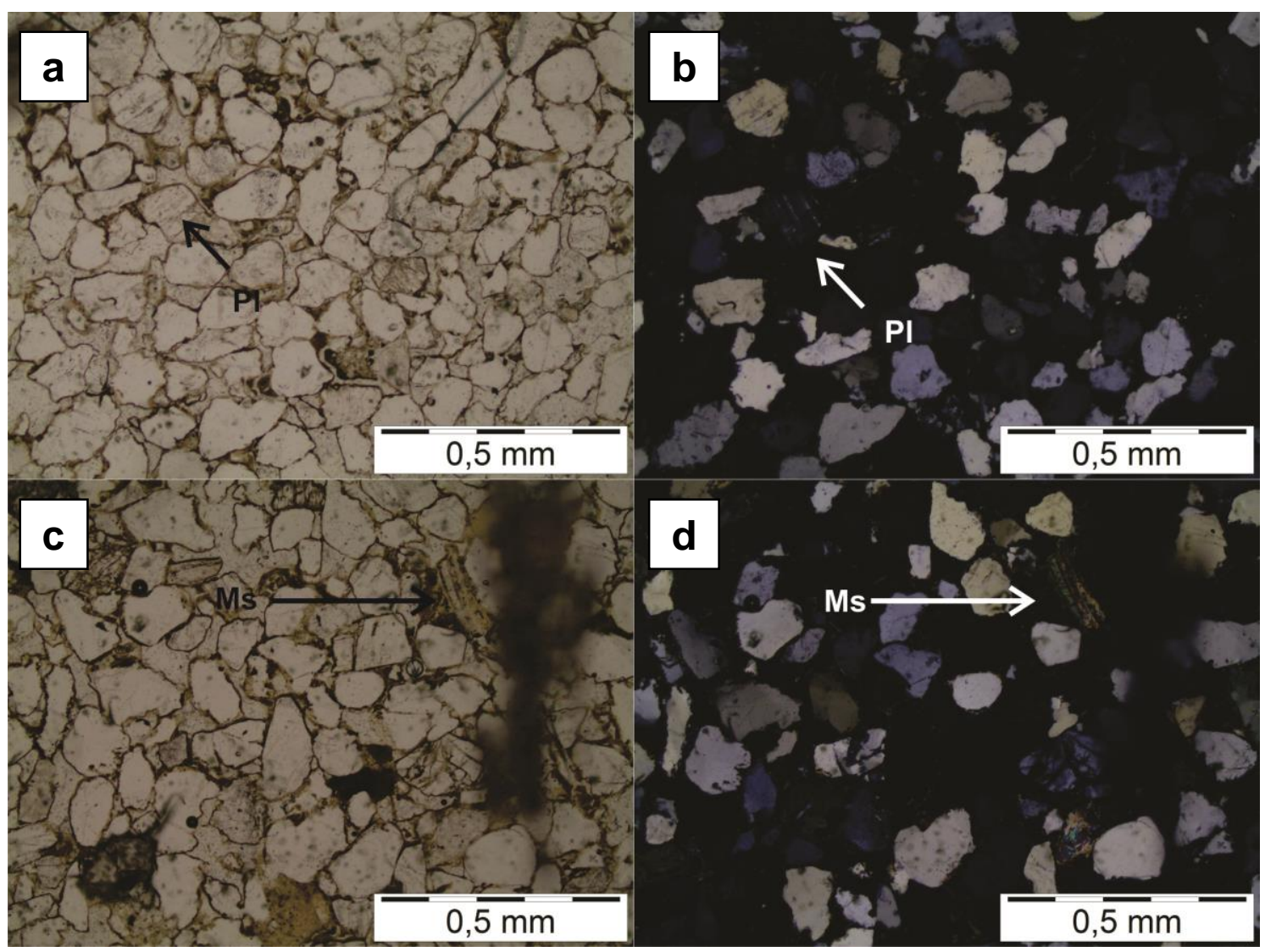

Figura 10. Fotomicrografia dos arenitos fluviais da Formação São Sebastião ( $\mathrm{Pl}=$ plagioclásio; $\mathrm{Ms}=$ muscovita). Nicois paralelos (a, c); Nicois cruzados (b, d). 


\section{Sequência Eólica}

A segunda fácies diz respeito ao retrabalhamento eólico da primeira fácies. Está representada por arenitos finos, às vezes médios, esbranquiçados a amarelados, bem selecionados, apresentando uma bimodalidade dos grãos de quartzo que são arredondados. Além dessas características, as estratificações cruzadas planares de alto ângulo que são típicas de ambientes eólicos também são encontradas nessa unidade, mais precisamente nesses arenitos finos a médios, definindo assim essa segunda fácies (Fig. 11 e 12).

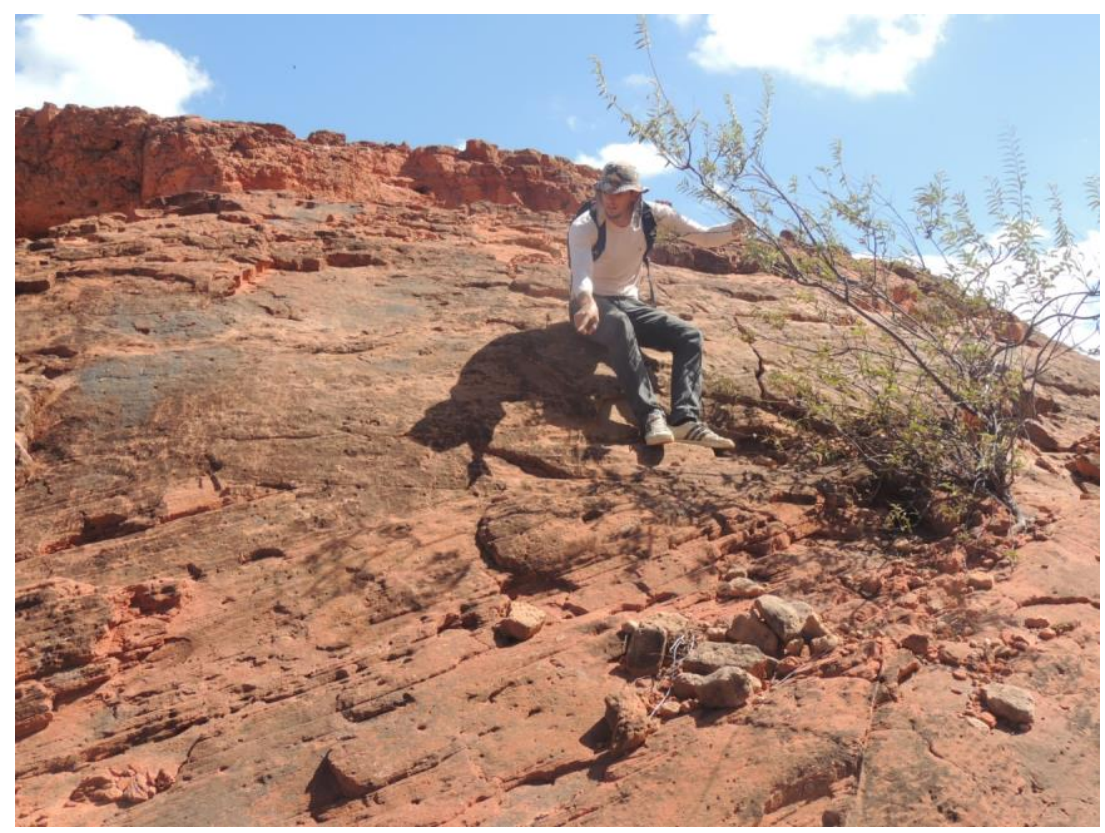

Figura 11. Estratificação cruzada planar de alto ângulo da fácies eólica da Formação São Sebastião.

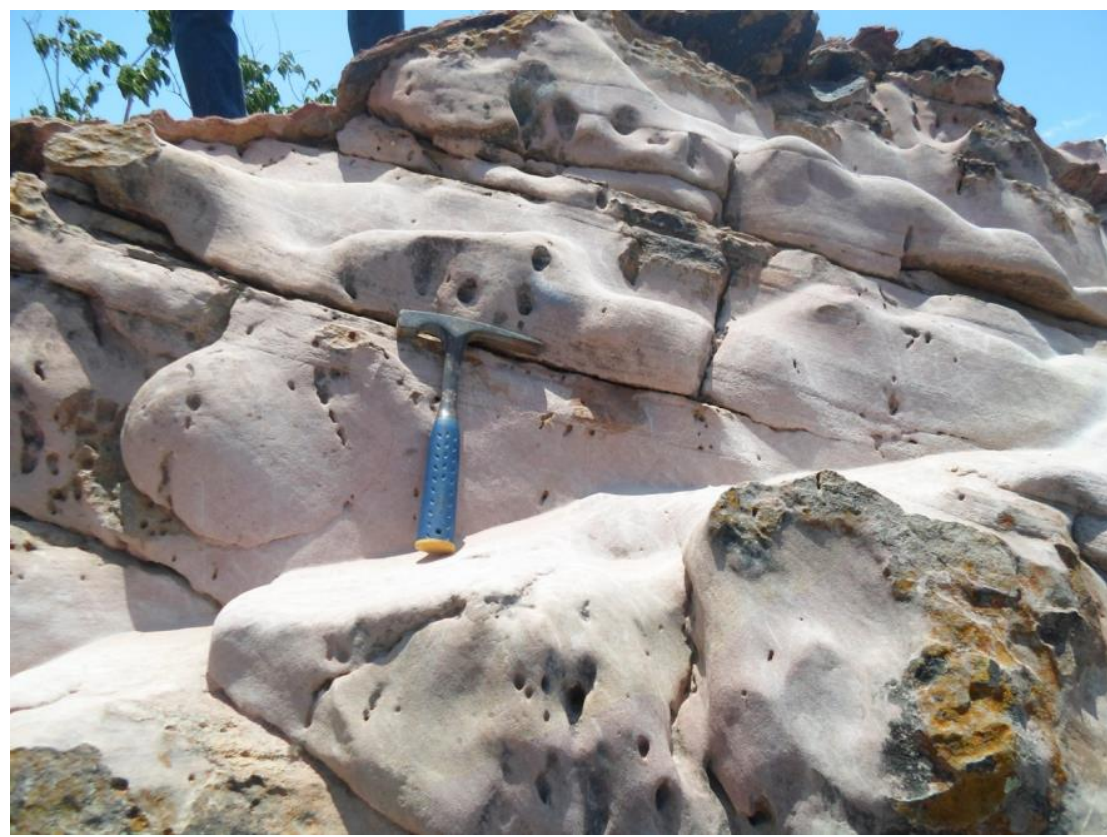

Figura 12. Estratificação cruzada planar de alto ângulo da fácies eólica da Formação São Sebastião. 
A fácies eólica é diferenciada por apresentar uma bimodalidade dos grãos, melhorando a sua seleção, possuem uma granulação mais fina e são grãos mais arredondados do que na fácies fluvial. Com isso, todas as características citadas anteriormente são equivalentes para as duas fácies, mantendo apenas essas poucas diferenças.

Apresentam-se maturos texturalmente, pois existe a predominância dos grãos subangulosos à subarredondados. E de acordo com o índice de Folk (M), de maturidade mineralógica, o sedimento é dito como maturo devido ao alto valor de quartzo em relação ao feldspato.

Petrograficamente, segundo a classificação de Folk (1968), os arenitos da Formação São Sebastião classificam-se como Quartzoarenitos (Fig. 14).

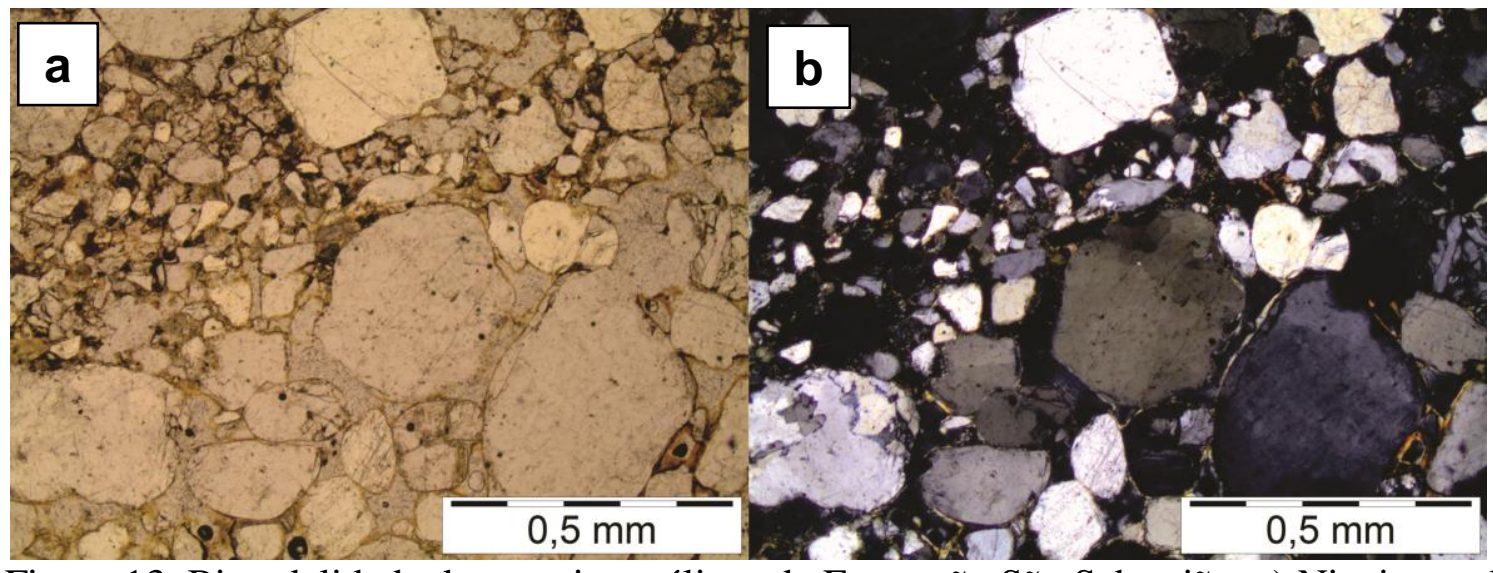

Figura 13. Bimodalidade dos arenitos eólicos da Formação São Sebastião. a) Nicois paralelos; b) Nicois cruzados.

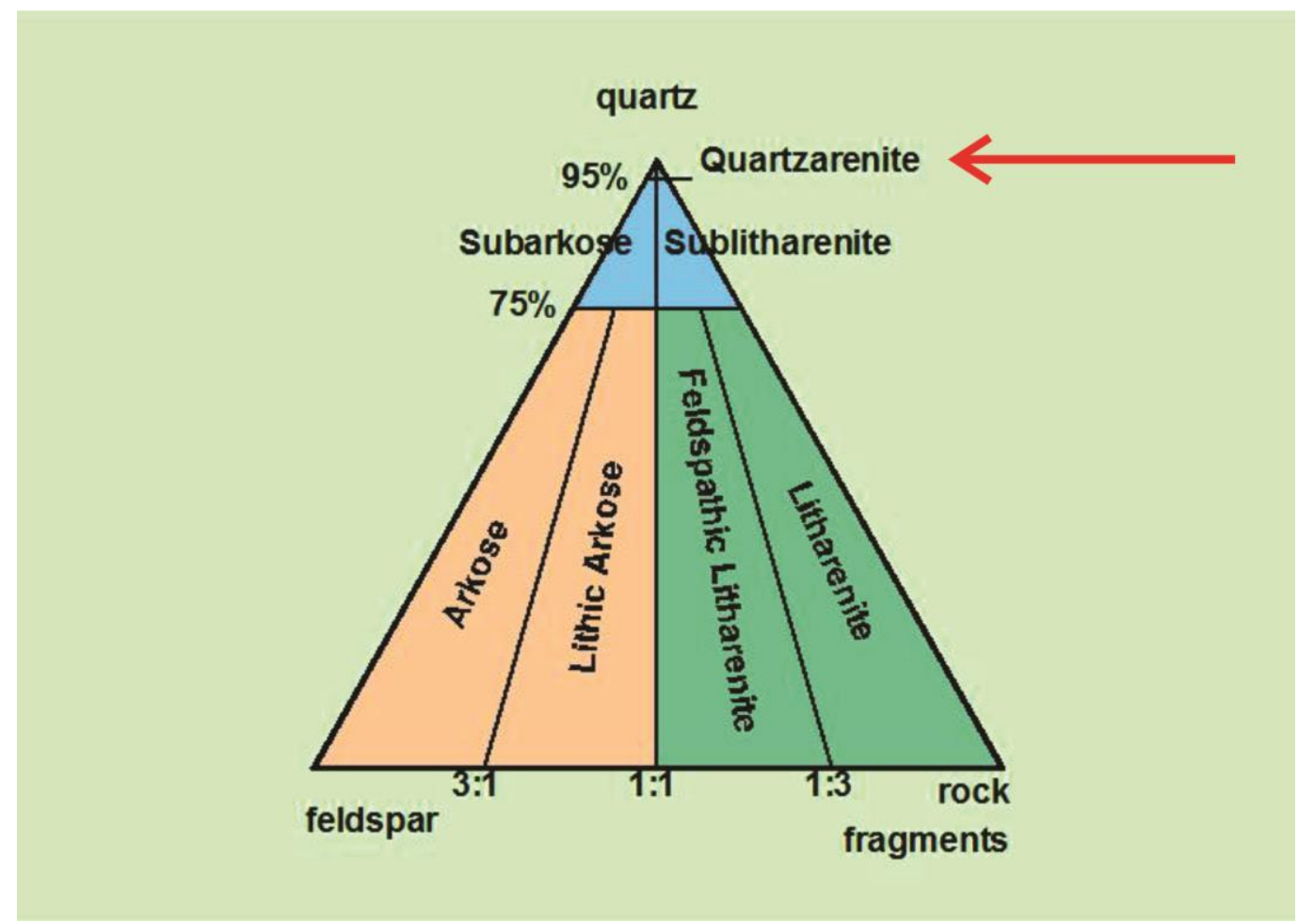

Figura 14. Ternário de classificação de arenitos de Folk (1968). 


\section{CONCLUSÕES}

A Formação São Sebastião está constituída por duas fácies, a primeira representada pela fácies fluvial e a segunda, eólica.

A fácies fluvial é composta por arenitos muito finos a grossos, ainda contendo muscovita e plagioclásio, considerando que o ambiente é de alta energia já que também foram encontrados seixos em sua composição. Enquanto que, a segunda, é representada por arenitos finos a médios apresentando uma bimodalidade no tamanho dos grãos de quartzo e como estruturas marcantes as estratificações cruzadas planares de alto ângulo, caracterizando um ambiente eólico.

$\mathrm{O}$ estudo petrográfico confirma e complementa os dados observados em campo no que diz respeito à composição dos arenitos e suas características. Ambas as fácies são classificadas como quartzoarenitos, de acordo com Folk (1968).

Com todos os dados obtidos e as relevâncias a serem destacadas, pode-se concluir que houveram dois estágios de deposição: primeiramente, um sistema fluvial entrelaçado de alta energia identificado segundo uma sucessão de fácies características, e posteriormente, um retrabalhamento eólico desse primeiro estágio, evidenciado pelos grãos arredondados, bimodalidade destes grãos e estratificações cruzadas planares de alto ângulo.

\section{REFERÊNCIAS}

Bruni, M. A. L.; Cordani, U. G.; Campos, D. R. B; Campos, D. de A. 1976. Carta geológica do Brasil ao milionésimo. Folha Aracaju (SC. 24). Brasília: DNPM / DGM, 226p.

Costa, I. P.; Bueno, G. V.; Milhomem, P. S.; Silva, H. S. R. L.; Kosin, M. D. 2007. Sub-bacia de Tucano Norte e Bacia de
Jatobá. Boletim de Geociências da Petrobras, v.15, n.2, 445-453.

Fambrini, G. L., Lima Filho, M. F., Costa, B. H., Jesuíno, P. C. L., Tesser Jr., S. 2006. Sistemas fluviais entrelaçados de alta energia da Formação São Sebastião na Bacia de Jatobá, Nordeste do Brasil. In: Congresso Brasileiro de Geologia, 43, 2006. Anais, Aracaju, SBG, p. 289.

Fambrini, G. L., Lima Filho, M., Tesser Jr., S., Costa, B. H., Jesuíno, P. C. L., Valença, L. M. M., Neumann, V. H. 2007. Paleocorrentes fluviais da Formação São Sebastião, Bacia de Jatobá, NE do Brasil. In: Simpósio de Geologia do Nordeste, 22, 2007, Natal, Atas, SBG, p. 45.

Fambrini, G. L., Neumann, V. H., MenezesFilho, J. A. B., Rocha, D. E. G. A., Durval, L. G., Jesuíno, P. C. L. 2013. Fácies e sistemas deposicionais da Formação São Sebastião (Eocretáceo), Bacia de Jatobá, PE: contribuição à evolução geológica do Rifte Recôncavo-Tucano-Jatobá, Nordeste do Brasil. In: Simpósio de Geologia do Nordeste, 25, 2013, Gravatá, PE. Conferências e resumos, Boletim 23, p. 176-177.

Folk, R. L. 1968. Petrology of sedimentary rocks. The Univ. of Texas, Austin, Hemphil's, 1968. 172 p.

Guzmán-González, J., Fambrini, G. L., Usma, C. C., Oliveira, E. V. 2015. Estratigrafia da Bacia de Jatobá: Estado da Arte. Estudos Geológicos, v. 25 (1), p. 53-76.

Miall, A. D. 1996. The geology of fluvial deposits: sedimentary facies, basin analysis and petroleum geology. Berlin, Springer, 582 p.

Mountney, N. P. Eolian facies models. In: Posamentier, H. W. \& Walker, R. G. (Eds.). Facies Models Revisited. Society for Sedimentary Geology, Special Publication, 84, p. 19-83, 2006. 
Neumann, V. H.; Rocha, D. G. A.; Moraes, A. S.; Sial, A. N.; Taboada-Castro, M. T.; Barbosa, J. A.; Fambrini, G. L.; Carvalho, R. R. 2010. Microfácies carbonáticas e comportamento isotópico de $\mathrm{C}$ e $\mathrm{O}$ nos calcários laminados aptianos lacustres da Serra Negra, bacia de Jatobá, Nordeste do Brasil. Estudos Geológicos, v. 20 (1), p. 89-100.

Ponte, F. C.; Medeiros, R. A.; Ponte Filho, F. C. 1997. Análise estratigráfica da Bacia do Araripe: Parte 1 - Análise de sequências. In: Simpósio sobre a Bacia do Araripe e Bacias interiores do Nordeste, 2, Crato -Ceará. Atas. Crato; DNPM.
Rocha, D. E. G. A.E Leite, J. F. 1999. Estudo Hidrogeológico da Bacia do Jatobá - Geologia. Recife. CPRM, 49 $\mathrm{p}$.

Veras, J. D. D.; Neumann, V. H.; Valença, L. M. M.; Madruga, M. M. D.; Oliveira, S. R. 2017. Mapeamento geológico da porção sudoeste da folha Airi, Bacia de Jatobá, nordeste do Brasil. Estudos Geológicos, v. 27 (1), p. $34-60$. 